\title{
Juvenile Stroke: Cervical Artery Dissection in a Patient after a Polytrauma
}

\author{
Nicole Marschner-Preuth ${ }^{\mathrm{a}, \mathrm{c}}$ Tobias Warnecke ${ }^{\mathrm{a}}$ \\ Thomas-Ulrich Niederstadt $^{b} \quad$ Ralf Dittrich $^{a} \quad$ Wolf-Rüdiger Schäbitz ${ }^{a, c}$ \\ Departments of ${ }^{a}$ Neurology and ${ }^{b}$ Radiology and X-Ray Diagnostics, University Hospital of \\ Münster, Münster, and ${ }^{C}$ Department of Neurology, Bethel Evangelisches Krankenhaus of \\ Bielefeld, Bielefeld, Germany
}

\section{Key Words}

Dissection $\cdot$ Juvenile stroke $\cdot$ Polytrauma $\cdot$ Pseudoaneurysm

\section{Abstract}

Dissections of the cervical arteries cause about $20 \%$ of total juvenile strokes. Approximately $4 \%$ of the carotid artery dissections are due to a (poly)trauma such as car accidents. Despite improved diagnostic facilities, traumatic dissections are often underdiagnosed or diagnosed too late due to a lack of awareness of potential initial signs and symptoms.

We report here a case of a delayed embolic stroke after a car accident caused by a dissection of the carotid artery and subsequent pseudoaneurysm.

To reduce the long-term morbidity or mortality of multiple trauma patients, an early detection of cervical carotid and vertebral dissections is strictly necessary.

\section{Introduction}

A stroke until the age of 45 [12] is called 'juvenile cerebral infarction'. In contrast to strokes in the elderly, juvenile strokes are often caused by rare pathologies [1], including dissections of the brain-supplying arteries, paradoxical embolism and thrombophilias [12]. Cervical dissections are the most frequent singular cause of juvenile strokes [2] and account for approximately $20 \%$ of acute strokes in young patients [13]. The majority of dissections occur spontaneously. In some cases they are acquired on the basis of connective tissue disease (e.g. Marfan, Ehlers-Danlos syndrome) or other predisposing factors [1, 12]. A 
specific constellation is a dissection of the brain-supplying arteries due to a trauma. Traumatic craniocervical dissections result from excessive speed, rotating or lash-like head movements, such as falls [5], car accidents [5] or other mild traumas [12]. Traumatic dissections are often diagnosed too late due to a lack of awareness of potential initial signs. Results of occurrence of cervical artery dissections after a trauma differ in several studies. The incidence of dissections of the internal carotid artery after a trauma ranges from 0.08 to $3.7 \%$ [9]. There are no reliable data for traumatic dissected vertebral arteries. It can be ensured more than half of the patients with dissections suffer from delayed cerebral infarctions or transient ischemic episodes. Over $80 \%$ of these events occur within the first week after onset of symptoms. The rest occur partially up to a month later [4], some by formation of pseudoaneurysms and subsequent embolism [8]. Pseudoaneurysms develop in $20-40 \%$ of the cases [4]. Clinical predictors of possible dissections of the carotid arteries include visible skull fractures, e.g. Le Fort type II and III and diffuse brain injuries (Glasgow Coma Scale of <6) [3]. Furthermore, strangulating traces by a seat belt injury [15], cervical swelling, cervical sounds under auscultation, expanding cervical hematomas, or focal neurological deficits (particularly painful Horner's syndrome) [12] are suspicious.

\section{Case Presentation}

A 16-year-old patient suffered from injuries sustained in a car accident by a collision with another vehicle. His car veered into the opposite lane. After the accident the patient was briefly muzzy, but not unconscious. There were multiple contusions and bruises, including the left knee, the chest (seat belt injury) and the left neck. A massive hematoma with severe restriction of movement was found in the left leg. In hospital, a concussion, a cervical spine sprain and multiple bruises were diagnosed. The patient was discharged after five days. Three months later, the patient came to our hospital emergency department after he suddenly developed a sensorimotor hemiparesis on the right. The clinical diagnosis of a stroke was made. The MRI showed an embolic infarction of the left anterior basal ganglia and the left internal capsule (fig. 1) due to a pseudoaneurysm of the left internal carotid artery (fig. 2, fig. 3). We started oral anticoagulation with phenprocoumon for 6 months to prevent further thromboembolic events. Over the course of one month the patient displayed an almost complete recovery with remaining mild facial palsy on the right.

\section{Discussion}

In the present case, signs of a traumatic cervical artery dissection immediately after the accident were overlooked. In the acute setting, focal neurological deficits were absent. An expanding cervical hematoma was initially documented and primarily attributed to a typical seat belt injury. Targeted investigations of the brain-supplying arteries were not done, resulting in the serious complication of a stroke in the region of the basal ganglia, occurring with a time lag of three months.

This case illustrates the importance of awareness for clinical signs of cervical artery dissections after a polytrauma, especially as we know about the high incidence of trauma in the groups of younger-aged and middle-aged patients [10] and the known coincidence between polytrauma and stroke [3]. An incalculable factor is a delayed rupture of the intramural hematoma, which can lead to subsequent embolism by the formation of pseudoaneurysms [8]. There exists no special therapeutic guideline for traumatic cervical 
artery dissection of patients with polytrauma. The medical treatment of traumatic cervical artery dissection is similar to spontaneous cervical artery dissections. In the acute phase of an ischemia as a result of a cervical artery dissection, a systemic thrombolysis is a possible therapeutic strategy according to stroke guidelines $[1,7]$. However, the balance between beneficial effects and side effects of thrombolysis in patients with polytrauma must carefully be considered.

No randomized data exist for the use of local thrombolysis in such cases. Even more important is the initiation of an appropriate preventive strategy to avoid thromboembolic complications caused by the dissected artery. Different studies show that both antiplatelets and anticoagulation are effective without any clear advantage for one of the two therapies [6]. It has been proposed that an induced hypertension or an endovascular intervention for improving perfusion is justified in single cases. [4] According to guidelines [1, 4], it is suggested to start with heparin followed by an anticoagulation therapy for 3-24 months. A long-term treatment with aspirin is recommended because the risk of an ischemic complication in the future is not predictable. In chronic stage after 6 months of anticoagulation, if an aneurysms or a high-grade carotid stenosis persisted or have newly developed, a surgical intervention could be considered to prevent further ischemic events $[11,14]$. In the present case we recommended continuing the oral anticoagulation for 6 months. We agreed a checkup 6 months after discharge with an imaging control to discuss the further procedure.

In summary, multiple trauma patients have an almost $4 \%$ risk of a cervical internal carotid artery dissection. To reduce the long-term morbidity or mortality of multiple trauma patients, an early detection of cervical carotid and vertebral dissections is strictly necessary. Diagnosis must particularly be precluded by the presence of skull fractures [3] or when a cervical sound is noticed under auscultation, or an expanding cervical hematoma or other focal neurological symptoms (especially Horner's syndrome) exist [12].

\section{Disclosure Statement}

The authors have nothing to disclose.

\section{References}

1 Brott TG, Halperin JL, Abbara S, Bacharach JM, Barr JD, Bush RL, Cates CU, Creager MA, Fowler SB, Friday G, Hertzberg VS, McIff EB, Moore WS, Panagos PD, Riles TS, Rosenwasser RH, Taylor AJ: Guideline on the Management of Patients With Extracranial Carotid and Vertebral Artery Disease: A Report of the American College of Cardiology Foundation/American Heart Association Task Force on Practice Guidelines, and the American Stroke Association, American Association of Neuroscience Nurses, American Association of Neurological Surgeons, American College of Radiology, American Society of Neuroradiology, Congress of Neurological Surgeons, Society of Atherosclerosis Imaging and Prevention, Society for Cardiovascular Angiography and Interventions, Society of Interventional Radiology, Society of NeuroInterventional Surgery, Society for Vascular Medicine, and Society for Vascular Surgery. Circulation 2011;124:e54-e130.

-2 Baumgartner RW, Arnold M, Baumgartner I, Mosso M, Gönner F, Studer A, Schroth G, Schuknecht B, Sturzenegger M: Carotid dissection with and without ischemic events. Neurology 2001;57:827-832.

-3 Blacker DJ, Wijdicks EFM: Clinical characteristics and mechanisms of stroke after polytrauma. Mayo Clin Proc 2004;79:630-635.

4 Diener HC (ed): Leitlinien für Diagnostik und Therapie in der Neurologie: Dissektionen hirnversorgender supraaortaler Arterien. Stuttgart, Georg Thieme Verlag, 2008.

5 Dziewas R, Konrad C, Dräger B, Evers S, Besselmann M, Luedemann P, et al: Cervical artery dissectionclinical features, risk factors, therapy and outcome in 126 patients. J Neurol 2003;250:1179-1184.

6 Engelter ST, Brandt T, Debette S, Caso V, Lichy C, Pezzini A, Abboud S, Bersano A, Dittrich R, Grond-Ginsbach C, Hausser I, Kloss M, Grau AJ, Tatlisumak T, Leys D, Lyrer PA: Antiplatelets versus anticoagulation in cervical artery dissection. Stroke 2007;38:2605-2611. 
Marschner-Preuth et al.: Juvenile Stroke: Cervical Artery Dissection in a Patient after a Polytrauma

7 Georgiadis D, Baumgartner RW: Thrombolysis in cervical artery dissection. Front Neurol Neurosci 2005;20:140-146.

8 Guillon B, Brunereau L, Biousse V, Djouhri H, Levy C, Bousser MG: Long-term follow-up of aneurysms developed during extracranial internal carotid artery dissection. Neurology 1999;53:117-122.

-9 Hughes KM, Collier B, Greene KA, Kurek S: Traumatic carotid artery dissection: a significant incidental finding. Am Surg 2000;66:1023-1027.

10 Lenz M, Bula-Sternberg J, Koch T, Bula P, Bonnaire F: Traumatic dissection of the internal carotid artery following whiplash injury. Diagnostic workup and therapy of an often overlooked but potentially dangerous additional vascular lesion. Unfallchirurg 2012;115:369-376.

-11 Muller BT, Luther B, Hort W, Neumann-Haefelin T, Aulich A, Sandmann W: Surgical treatment of 50 carotid dissections: indications and results. J Vasc Surg 2000;31:980-988.

12 Nabavi DG, Allroggen A, Ringelstein EB: Der juvenile ischämische Insult. Nervenarzt 2004;75:167-186.

13 Redekop GJ: Extracranial carotid and vertebral artery dissection: a review. Can J Neurol Sci 2008;35:146152.

14 Seth R, Obuchowski AM, Zoarski GH: Endovascular repair of traumatic cervical internal carotid artery injuries: a safe and effective treatment option. AJNR 2012, DOI: 10.3174/ajnr.A3337.

15 Teifke A, Degreif J, Geist M, Schild H, Strunk H, Strunk K: Der Sicherheitsgurt: Auswirkungen auf das Verletzungsmuster von Autoinsassen. Fortschr Röntgenstr 1993;159:278-283.

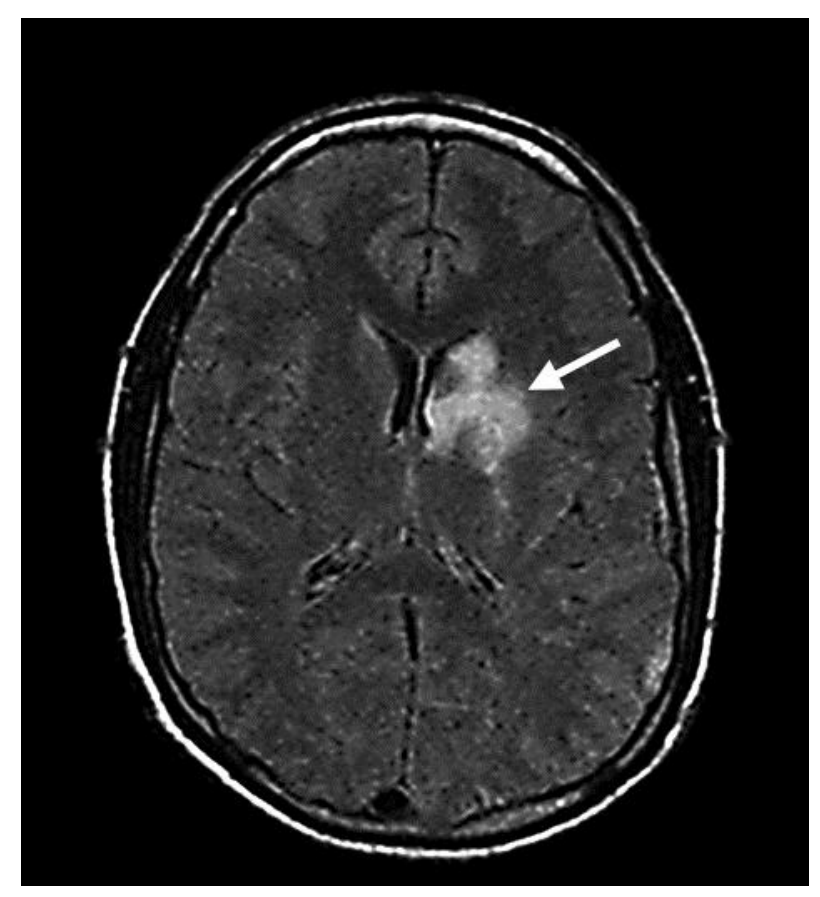

Fig. 1. Diagnostic imaging (MRI): transverse plane through the brain to the lateral ventricles. The T2weighted FLAIR image shows an infarction of the left anterior basal ganglia and internal capsule (arrow). 


\section{Case Reports in Neurology}

\begin{tabular}{l|l}
\hline Case Rep Neurol 2013;5:21-25 & \\
\hline DOI: $\underline{10.1159 / 000347001}$ & $\begin{array}{l}\text { @ } 2013 \text { S. Karger AG, Basel } \\
\text { www.karger.com/crn }\end{array}$ \\
\hline
\end{tabular}

Marschner-Preuth et al:: Juvenile Stroke: Cervical Artery Dissection in a Patient after a Polytrauma

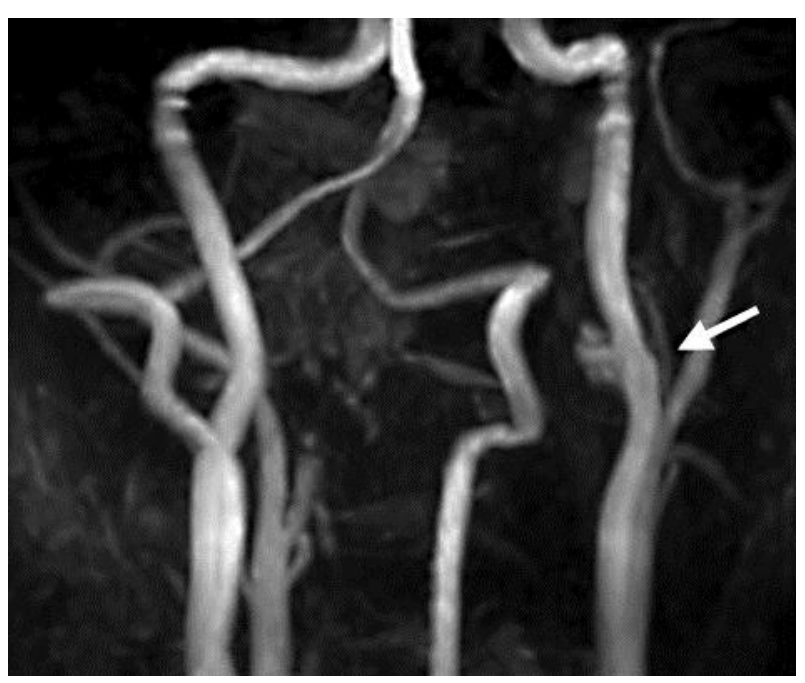

Fig. 2. The TOF (time of flight) MR angiography reveals a pseudoaneurysm (arrow) of the left distal carotid artery.
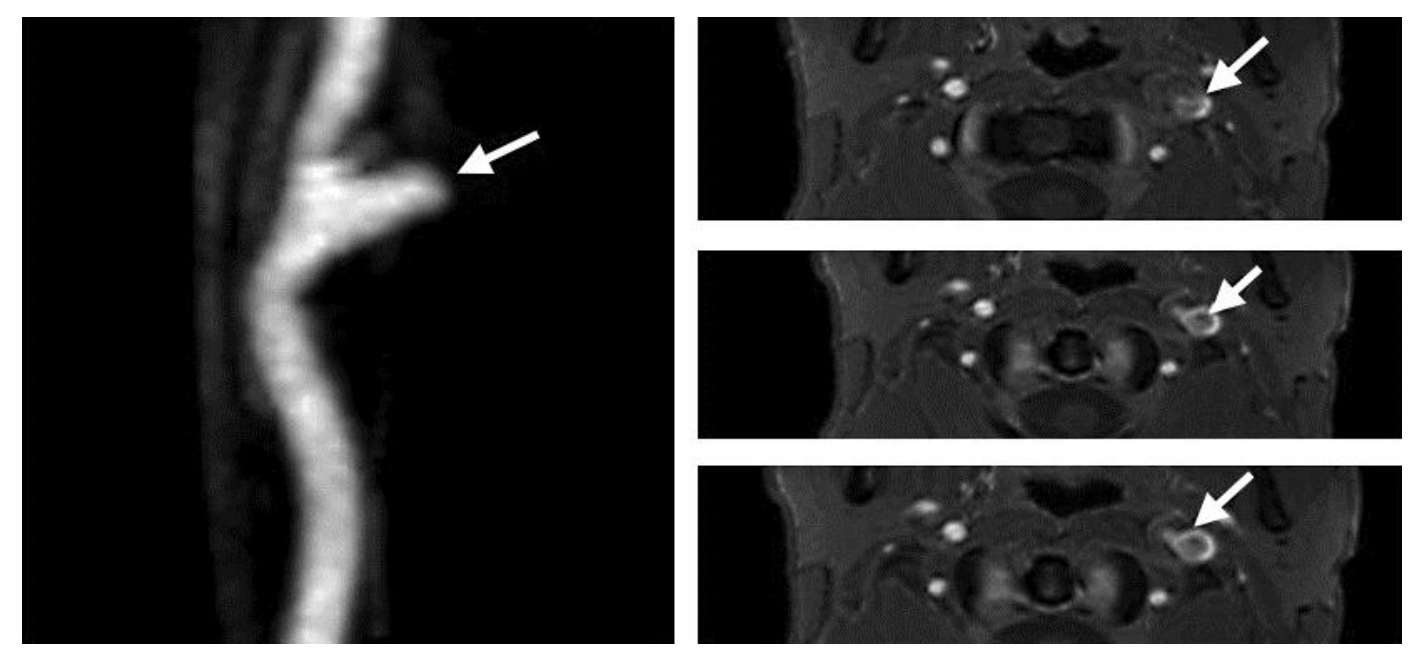

Fig. 3. Enlarged view of the pseudoaneurysm of the left internal carotid artery (left figure). The pseudoaneurysm (arrow) has connection to the vascular system (crescent-shaped white structure). 